\title{
Foaling Rate and Survival of Feral Horses in Western Nevada
}

\author{
DONALD B. SINIFF, JOHN R. TESTER AND GREGORY L. MCMAHON
}

\begin{abstract}
Foaling and mortality rates of known-age feral horses equipped with radio transmitters were obtained in 1981 and 1982 for 2 areas in Nevada. These data showed considerable annual variation. In one area, $45 \%$ of the mares produced foals in both years while only $10 \%$ produced foals in the other area. Foal mortality ranged from $2 \%$ to $33 \%$. Both the highest mortality (33\% in 1981) and the lowest (2\% in 1982) occurred in the same area. The cause for this apparent inconsistency was unknown. The highest age-specific reproductive rates occurred in 5 to 10 year-old mares.
\end{abstract}

Few data on feral horse survival and foaling rates are available in the literature. Foaling rates have varied considerably from one area to the next and among age classes. For mares 4 years and older the rate varies from $42 \%$ to $78 \%$ (Tyler 1972, Welsh 1975, Feist and McCullough 1975, Keiper 1979, Nelson 1979, and Boyd 1980). Foal survival was reported by Feist and McCullough (1975) from birth in the spring until 1 November at $89 \%$, with Boyd (1980) estimating foal survival at $82 \%$ for the first year of life.

This paper reports foaling and mortality rates of known-age marked mares in 2 feral horse populations. The study was conducted during 1981 and 1982 in western Nevada.

\section{Study Areas and Methods}

The Pah Rah Mustang Area of 74,460 ha, northeast of Sparks, Nevada, had a feral horse population estimated by mark-recapture techniques using known transmittered animals as the marked sample, at $800-1,000$ individuals during this study. The area has rugged topography with a maximum elevation of $2,590 \mathrm{~m}, 1,067 \mathrm{~m}$ above the valley floor. It is dissected by numerous canyons. Most of the area is dominated by sagebrush (Artemisia spp.) and rabbitbrush (Chrysothamnus spp.) with smaller areas dominated by cheatgrass (Bromus tectorum) and various annual forbs.

The 130,364-ha Pine Nut Mountain Range east of Carson City, Nevada, is also rugged topographically with a maximum elevation of over $2,900 \mathrm{~m}$. The feral horse population was estimated, again by mark-recapture techniques using known transmittered animals as the marked sample, at $700-1,000$ individuals. Vegetation there was predominantly pinyon-juniper (Pinus monophylla-Juniperus osteosperma), with smaller areas dominated by rabbitbrush and sagebrush.

Numbered collars with and without radio transmitters were placed on 48 horses in 1980-81 and 41 more in 1982 for the Pah Rah area, and 51 in 1980-81 and 29 more in 1982 for the Pine Nut area. All collars were constructed of 10-cm-wide, 3-ply white food conveyor belting. The white belting was tapered to $3.8 \mathrm{~cm}$ wide in the area under the neck to minimize wear and irritation. All collars were numbered with $5.0 \times 7.6-\mathrm{cm}$ orange or yellow cattle tags. Radio transmitters placed on horses during 1980 and 1981 had an estimated battery life of 2 years while the 1982 transmitters had an expected life of 4 years.

Horses collared in 1980-81 were captured using conventional Bureau of Land Management gathering techniques with helicop-

\footnotetext{
The authors are two professors and a former graduate student in the Department of Ecology and Behavioral Biology. University of Minnesota, Minneapolis 55455. The research was part of a project on evaluation of census techniques for feral horses funded by BLM contract AA851-CTO-52. We are grateful to Bureau of Land Management personnel of the Carson City District who provided invaluable help in capture and collaring of horses. T. Owen, T. Reuwsad, P. Anderson, D. Pomi, and B. Stewart assisted throughout the project. M Frei, Nevada State Office, provided valuable guidance and support.

Manuscript accepted 14 November 1985.
}

ters. Horses collared in 1982 were immobolized from helicopters with a Rompun-M99 combination (Seal et al. 1985). All were aged by standard tooth wear criterion by veterinarians or persons knowledgeable about horses during the handling process. There was probably some error associated with these readings but designed tests of precision were not possible. However, such errors would be small in the calculation of rates.

Most foal and mortality observations were made during census flights on the study areas. The typical procedure involved a helicopter flight of the area during which all collared horses that were encountered during the flight were noted and their foaling status was observed. We found it more cost effective to conduct follow-up flights using a Piper Supercub to locate radio-collared horses missed during the helicopter flight. This was meant to maximize sample size and detect any mortality or tag loss that might have occurred. On a few occasions, only the Supercub was used to make observations. Flights were conducted on 5 May, 3 July, and 7 September in 1981, and 6-7 May, 2 July, 27 July, and 19 September in 1982 for the Pah Rah areas, and 7-8 May, 2-3 July, and 21 July in 1981, and 20-22 May, 2-3 July, 28 July, and 18 September in 1982 for the Pine Nut Mountains.

Ground observations were made during both 1981 and 1982 to confirm aerial observations and to increase the sample size of observed horses. These observations were made from horseback, vehicles, and on foot.

It should be emphasized that foaling and foal mortality rates represent minimum estimates. Given the frequency of observations, it is possible that a mare could have foaled and the foal died in the time period between observations. If this occurred, the mare would have been recorded as having never foaled and the foal mortality would have been missed.

\section{Results and Discussion}

Foaling rates were comparable for both years on the Pah Rah Mustang Area (Table 1). On the Pine Nut Mountains, foaling appeared lower in 1982 than in 1981 but was not significantly so at the .05 level (Chi-square criterion). Since there were no statistical differences between years within areas, the data were pooled across years for each area and tested for differences between areas. Foaling rates were significantly greater on the Pah Rah than the Pine Nut area (Chi-square criterion, $p<.01$ ). On the Pah Rah area $45 \%$ of the observed mares foaled both years while only $10 \%$ foaled both

Table 1. Foaling summary for Pine Nut Mountain and Pah Rah Mustang areas in western Nevada for 1981 and 1982.

\begin{tabular}{|c|c|c|c|c|}
\hline & \multicolumn{2}{|c|}{ Pine Nut } & \multicolumn{2}{|c|}{ Pah Rah } \\
\hline & 1981 & 1982 & 1981 & 1982 \\
\hline Females & 38 & 66 & 39 & 70 \\
\hline Foals & 20 & 20 & 25 & 48 \\
\hline Foaling Rate & .53 & .30 & .64 & .69 \\
\hline Foal Mortalities & 3 & 2 & 8 & 1 \\
\hline Foal Mortality Rate & .15 & .10 & .33 & .02 \\
\hline Females Foaling Both Years & \multicolumn{2}{|c|}{$3(10 \%)$} & \multicolumn{2}{|c|}{$13(45 \%)$} \\
\hline Females Foaling 1 of 2 Years & \multicolumn{2}{|c|}{$18(62 \%)$} & \multicolumn{2}{|c|}{$10(34 \%)$} \\
\hline Females Not Foaling & \multirow{2}{*}{\multicolumn{2}{|c|}{$8(28 \%)$}} & & \\
\hline Either Year & & & \multicolumn{2}{|c|}{$6(21 \%)$} \\
\hline
\end{tabular}




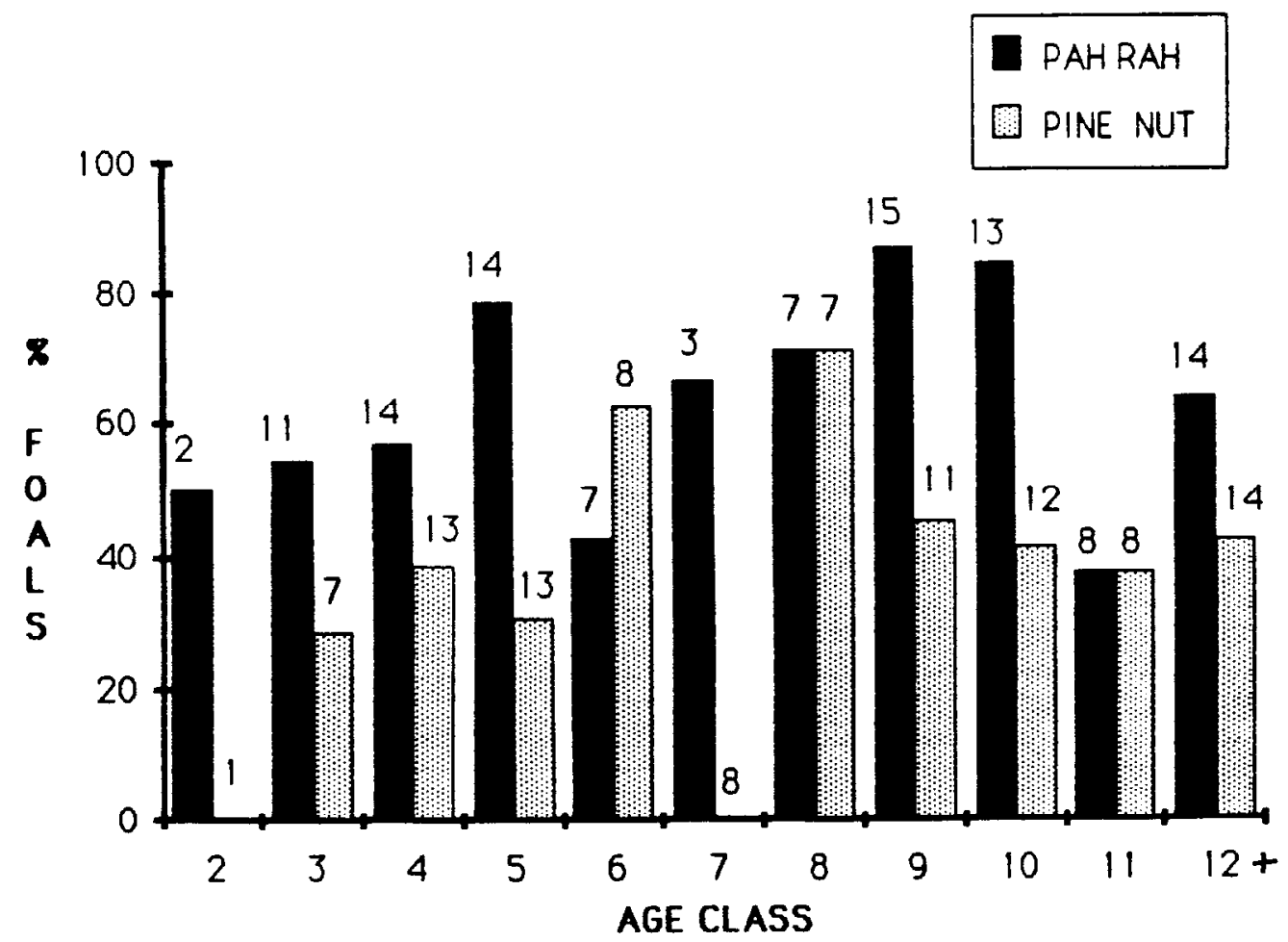

Fig. 1. Age-specific foaling rates for 1981 and 1982, combined, on the Pah Rah Mustang and Pine Nut Mountain areas in western Nevada. Numbers above bars indicate sample sizes.

years on the Pine Nut Mountains. Foal mortality rates, however, ranged from 2 to $33 \%$ over the 2 years on the Pah Rah area but from only 10 to $15 \%$ on the Pine Nut area (Table 1).

Age-specific foaling data combined for 1981 and 1982 (Fig. 1) reveal that the highest reproductive rates occurred in 5- to 10-yearold mares on both areas. Data for both years are pooled in Figure I because our sample sizes would have been too small to consider annual age-specific reproductive rates during each year individually. The fact that one 2-year-old mare had a foal indicates that this age class can reproduce. It is also important to note that mares 12 years and older had reproductive rates of 64 and $43 \%$ on the Pah Rah and Pine Nut areas, respectively.

One radio-marked adult mare was found dead on each area during each of the years. On the Pine Nut Mountains both individuals were over 12 years in age while on the Pah Rah Mustang Area mares aged 8 and 9 years were found dead. Scavengers and decomposition made it impossible to determine the cause of mortality.

Adult female mortality rates can be estimated from the number of radio-collared females observed. For the Pah Rah Mustang Area, during 1981, 1 mortality was observed for 25 radio-collared females $(4 \%)$ while only 1 mortality was observed for 56 radiocollared females ( $2 \%$ ) during 1982 . On the Pine Nut Mountains, during 1981, 1 mortality was observed for 22 radio collared females (4\%) and during 1982 only 1 mortality was observed for 50 females (2\%). Observations were from the entire year of 1981 but only the first 9 months of 1982 .

Differences in foaling rates between the Pah Rah Mustang Area and Pine Nut Mountains may be related to differences in ecological range conditions between these areas. Bureau of Land Management studies (Dept. of Interior 1982, Reno grazing environmental impact statement. Draft. BLM Carson City District, Nevada) indicate that the ecological range condition in the Pine Nut Mountains is mostly classified as poor. Eighty-three percent of the area was in the poor classification while $13 \%$ was listed as fair and $4 \%$ as good. On the Pah Rah Mustang Area, only $37 \%$ of the area was listed as poor while $44 \%$ was fair and $19 \%$ was good. While we have no evidence that these figures relate to range quality for horses, we feel some relationships may exist, and thus further study may be indicated.

Eberhardt et al. (1982) indicated annual population growth rates of $20 \%$ from the Beaty's Butte and Jackie's Butte herds in southeastern Oregon. The population statistics for foaling rates and survival on the Pah Rah area are similar to the findings of Eberhardt et al. (1982); however, the rate of increase on the Pine Nut area is much lower than they reported for their study areas in Oregon.

It is important to note the wide range of spatial and temporal variability in the data from our 2 study areas, which are approximately 30 miles apart. With the extreme values of $69 \%$ of mares foaling and $2 \%$ foal mortality, population increase could be dramatic. Conversely, a foaling rate of $30 \%$ with $10 \%$ foal mortality results in a much slower increase. While the explanation for this variability is unknown, it may be related to food resources. Such high variability over a small temporal and spatial scale indicates that caution must be exercised in extrapolating demographic data on feral horse herds to large geographic areas or over long time spans.

\section{Literature Cited}

Boyd, L.E. 1980. The mare-foal demography of feral horses in Wyoming's Red Desert. P. 185-204. In: R.H. Denniston, ed. Symposium on the Ecology and Behavior of Wild and Feral Equids. Univ. Wyoming, Laramie.

Eberhardt, L.L., A.K. Majorowicz, and J.A. Wilcox. 1982. Apparent rates of increase for two feral horse herds. J. Wildl. Manage. 46:367-374.

Feist, J.D., and D. McCullough. 1975. Reproduction in feral horses. Reprod. Fertil. 23:13-18.

Keiper, R.R. 1979. Population dynamics of feral ponies. P. 175-183. In: R.H. Denniston, ed. Symposium on the ecology and behavior of wild and feral equids. Univ. Wyoming, Laramie.

Nelson, K.J. 1979. On the question of male-limited population growth in feral horses (Equus caballus). M.S. Thesis, New Mexico State University.

Seal, U.S., D.B. Siniff, J.R. Tester and T.D. Williams. 1985. Chemical immobilization and blood analysis of feral horses (Equus caballus). J. Wildl. Disease 21:411-416.

Tyler, S.J. 1972. The behavior and social organization of the New Forest ponies. Anim. Behav. Monog. 5:85-196.

Welsh, D.A. 1975. Population, behavioral, and grazing ecology of the horse of Sable Island, Nova Scotia. Ph.D. Diss., Dalhousie Univ. 